http://www.jfas.info

\title{
DEVELOPING CUSTOMIZABLE DEFENCE MOBILE APPLICATION SYSTEM USABILITY EVALUATION SCALE (DEFENCE-MOASUES) USING EXPLORATORY FACTOR ANALYSIS (EFA)
}

\author{
A. F. A. Fadzlah \\ Department of Computer Science, Faculty of Science and Defence Technology, National \\ Defence University of Malaysia, 57000 Kuala Lumpur, Malaysia
}

Published online: 10 September 2017

\begin{abstract}
A Defence Mobile Application System Usability Evaluation Scale (Defence-MoASUES) was designed to support customization of items at the construct level and to examine the construct validity of the item. The defence training system studied was an android-based application system that supported cadet evaluation and reporting. Using Defence-MoASUES, a cross-sectional study was conducted to evaluate users' perception toward usability evaluation (effectiveness, efficiency and satisfaction measures) of android-based defence training application system. The scale's psychometric properties of Defence-MoASUES were analysed by conducting an exploratory factor analysis (EFA) test. The sample comprised 384 cadet officers from a defence university. As a result, the customization matches the specific tasks of a defence training system while retaining comparability at the construct level.
\end{abstract}

Keywords: usability evaluation scale; defence application system; mobile application system; exploratory factor analysis.

Author Correspondence, e-mail: amalina.farhi@upnm.edu.my doi: http://dx.doi.org/10.4314/jfas.v9i3s.8 


\section{INTRODUCTION}

Previous studies have been reported for a number of instruments designed to measure usability [1, 5-7]. Although validated instruments exist, it was reported the lacked the resources considering mobile usability and defence dimension factors [2]. In addition, failure to consider mobile and defence knowledge may lead to major obstacles to defence mobile application system adoption [3]. Thus, resulting predicting perception toward defence mobile application system usability evaluation a challenge.

In order to bridge these knowledge gaps, this study explored the Defence-MoASUES by considering multiple theories to integrate both objective and subjective measures for usability. As such, this study suggests a conceptual usability model based on ISO's (1998) usability definition [4]. These include the key usability indicator of effectiveness, efficiency and satisfaction. This study described customizable scale development and reports the initial assessment of Defence-MoASUES. Scale items were designed within the context of android-based application system for evaluating cadet officer. A description of the system precedes the description of scale development.

\subsection{Android-based Application System}

The android-based application system was developed to support both cadet trainer and cadet officer tasks. The primary goal of the system is to improve the effectiveness, efficiency and satisfaction of the evaluation and reporting processes in defence training session. Namely Android-based Evaluation and Reporting Application System (PeLaKad), this system provides functionality for cadet trainers to enter training marks and for cadet officers to request training reports. There are 4 objectives in the development of PeLaKad system, 1) design a portable system that is based on the Android platform, 2) implement a dogtag verification system using optical character recognition method, 3) build an evaluation system using multimedia technology support, and 4) develop an evaluation report delivery system using built-in sharing application. The flow chart of the PeLaKad system is shown in Fig. 1. 

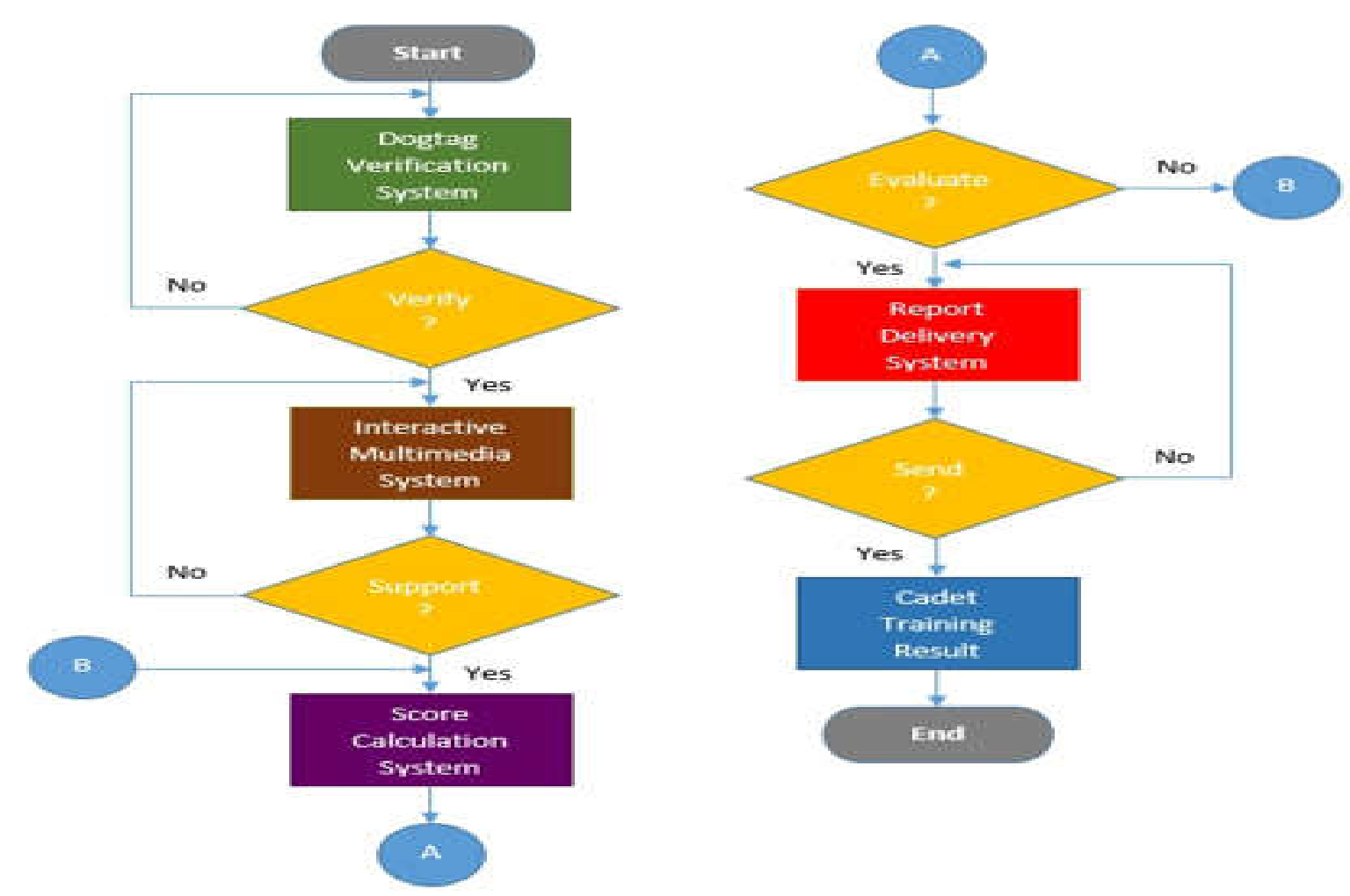

Fig.1. Flow chart of the PeLaKad system

The flow of the overall PeLaKad system is shown in Fig. 2.

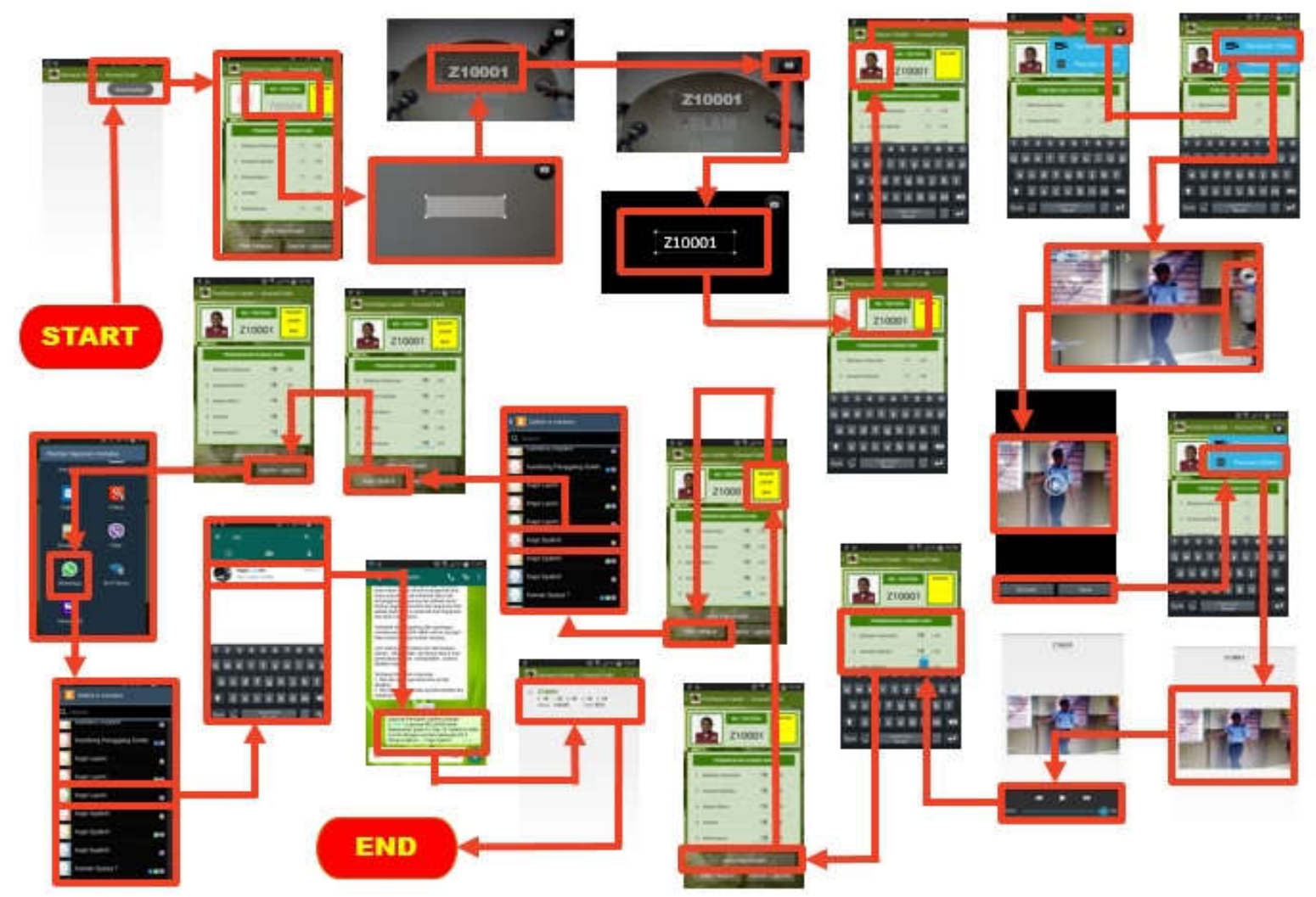

Fig.2. Flow chart of the overall PeLaKad system 
The system was developed using Waterfall Model which is based on 5 main phases namely planning, analysis, design, development and implementation of which indirectly focused on the usability design principles of effectiveness, efficiency and satisfaction to perform the evaluation of cadet training process. The methodology for the development of the PeLaKad system is shown in Fig. 3.

\subsection{Usability Evaluation Scale Development}

The iterative development of Defence-MoASUES was designed based upon numbers of proposed metrics for measuring usability. These metrics were collected and gathered by considering multiple theories to integrate both objective and subjective measures for usability evaluation. The construction of Defence-MoASUES items further includes conceptual mapping based upon the principle that usability can be measured by items of effectiveness, efficiency and satisfaction [9-12]. The items were modified to address the android-based application system and specific user tasks. For example, to modify the usability metric into question, 'number of tasks completed'. Thus results 'I think, it is important to measure the number of evaluation tasks completed by user within session or treatment' question.

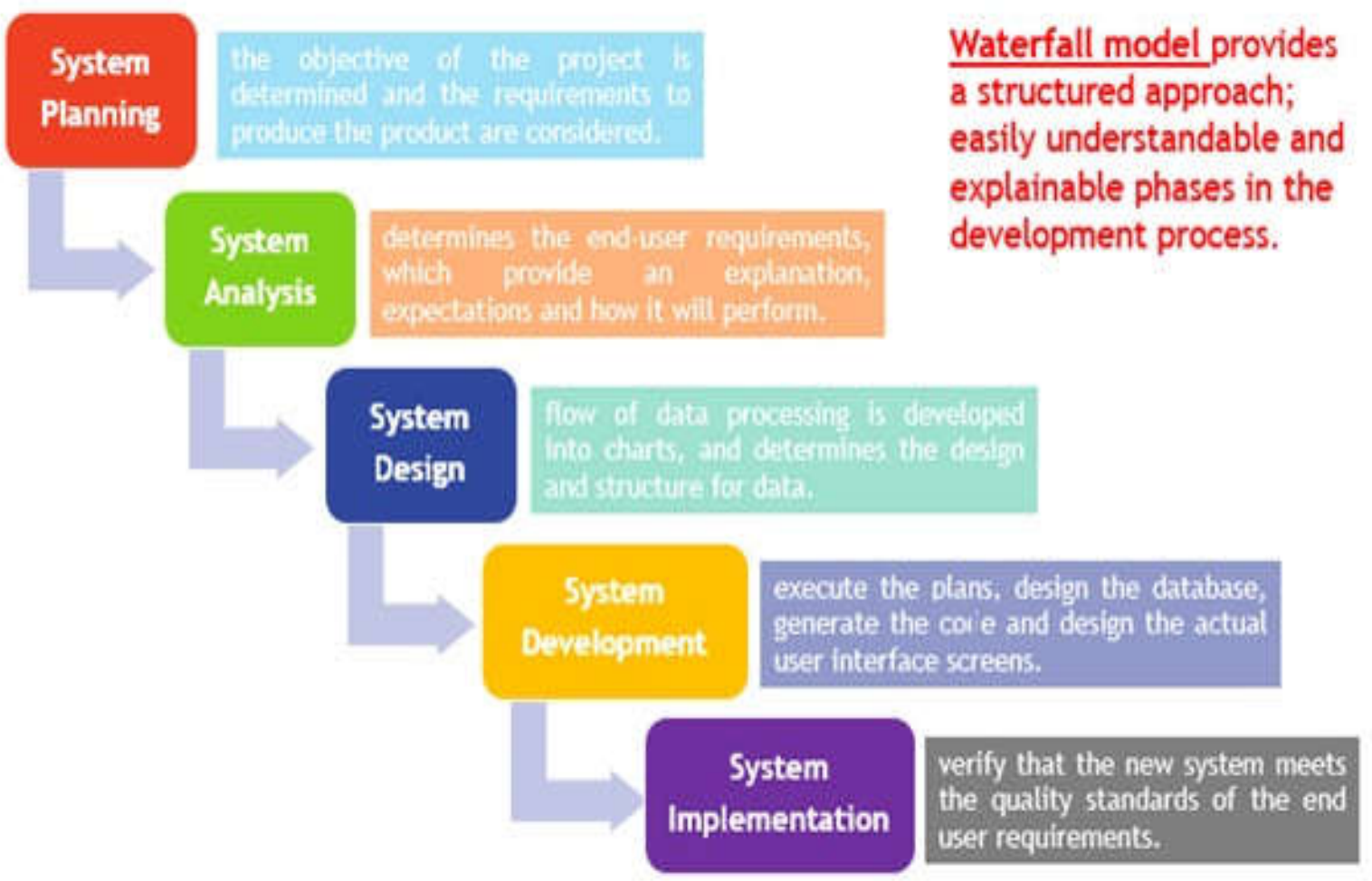

Fig.3. PeLaKad development

As a result, the Defence-MoASUES consisted of 18 items (refer Table 1): user willingness to 
complete task (User Willingness); ability to complete task (Task Completion); ability to correct error (Error Correction); ability to prevent error (Error Prevention); ability to achieve goal (Goal Achievement); ability to adapt skill (Skill Adaptation); task on time (Task Timeliness); speed of action (Action Speed); effort of usage (Usage Effort); stable in movement (Movement Steadiness); incisive in position (Position Stability); physical reaction toward usage (Physical Reaction); emotional feelings toward usage (Emotional Feeling); mental health toward usage (Mental Health); social wellbeing toward usage (Social Wellbeing), overall effectiveness toward usage (Usage Productivity), overall efficiency toward usage (User Competency) and overall satisfaction toward usage (Self Satisfaction). These Defence-MoASUES items rated on a five-point Likert scale from extremely disagree to extremely agree. A higher scale value indicates higher perception toward usability evaluation of the system.

Table 1. The categorization of the Defence-Moasues

\section{Item of Defence-MoASUES}

Q7 user willingness to complete task (i.e. number of users to complete task within session or treatment or allotted time); user completed $=1$; user withdrew $=0$

Q8 ability to complete task (i.e. number of tasks completed by user within session or treatment); task completed $=1$; task withdrew $=0$

Q9 ability to correct error (i.e. number of errors corrected by user while performing task); error corrected $=1$; error omitted $=0$

Q10 ability to prevent error (i.e. number of errors prevented by user while performing task); error prevented $=1$; error made $=0$

Q11 ability to achieve goal (i.e. number of goals achieved by user while performing task); goal achieved $=1$; goal failed $=0$

Q12 ability to adapt skill (i.e. number of skills adapted by user while performing task); skill adapted $=1 ;$ skill neglected $=0$

Q13 task on time (i.e. duration of time taken by user to complete performing task); task timely $=1 ;$ task delayed $=0$

Q14 speed of action (i.e. speed of action made per duration of time in performing task); 
fast action $=1$; slow action $=0$

Q15 effort of usage (i.e. frequency of effort taken by user to seek assistance in performing task); simple usage $=1$; difficult usage $=0$

Q16 stable in movement (i.e. angle of movement made by user to maintain stability in performing task); movement stabled $=1$; movement changed $=0$

Q17 incisive in position (i.e. length of position made by user to maintain stability in performing task); position stabled $=1$; position changed $=0$

Q18 physical reaction toward usage (i.e. number of physical reactions shown by user while performing task); accepted behaviour $=1$; rejected behaviour $=0$

Q19 emotional feelings toward usage (i.e. number of emotional feelings shown by user while performing task); positive feeling $=1$; negative feeling $=0$

Q20 mental health toward usage (i.e. number of mental health shown by user while performing task); normal health $=1$; abnormal health $=0$

Q21 social wellbeing toward usage (i.e. number of social wellbeing shown by user while performing task); balance wellbeing $=1$; unbalance wellbeing $=0$

Q22 overall effectiveness toward usage (i.e. number of overall effectiveness observed while performing task); task effective $=1$; task ineffective $=0$

Q23 overall efficiency toward usage (i.e. number of overall efficiency observed while performing task); task efficiency $=1$; task inefficiency $=0$

Q24 overall satisfaction toward usage i.e. number of overall satisfaction observed while performing task); task satisfied $=1$; task unsatisfied $=0$

\section{METHODOLOGY}

This paper presents a study following the procedure and process described in details, elsewhere [8]. A cross-sectional study was designed to evaluate users' perception toward usability evaluation of the android-based application system using Defence-MoASUES. The scale's psychometric properties of Defence-MoASUES were analysed by conducting an EFA test. 


\subsection{Setting and Sample}

The sample for the EFA was recruited from a defence university. At the time of questionnaire distribution, the android-based application system had been demonstrated once. Cadet Officers who had experienced the android-based application system met the inclusion criteria for study participation.

\subsection{Data Collection}

Questionnaires were manually distributed to eligible participants via in charged person for each battalion. An announcement regarding the opportunity to participate in the study was also posted on the social media page. The period of data collection was 1 week for the cadet officer sample. Questionnaires were considered complete when the amount of multiple data and missing data were less than $20 \%$. Demographic characteristics were collected from the cadet officer sample, and samples provided data on self-reported mobile usage competency.

\subsection{Data Analysis}

EFA was used to explore the psychometric characteristics of the Defence-MoASUES items. The Defence-MoASUES item communalities were first examined followed by parallel analysis and minimum average partial test was performed. These tests were used to determine the number of factors extracted and to access the stability of the factor solution across rotation types. Defence-MoASUES item reduction was also applied based upon item loadings and the procedures were repeated until reached Cronbach's alpha reliabilities.

\section{RESULTS AND DISCUSSION}

Results for this study are presented in the following order of descriptive analysis, factor analysis, power analysis and construct validity.

\subsection{Descriptive Analysis}

A total number of 397 cadet officers from the defence university responded. After exclusion of duplicate entries and missing entries (more than $3.27 \%$ of incomplete data), there were 384 valid responses. This study used list wise deletion for missing and duplicate data, therefore only valid responses were used in the EFA. The perceived mobile usage competency of the respondents was high. Results reported more than $50 \%$ of cadet officer respondents somewhat 
agreeing, strongly agreeing and extremely agreeing that they were competent. The mobile usage background of the cadet officer participants is summarized in Table 2.

Table 2. Mobile usage background

\begin{tabular}{|c|c|c|}
\hline Variable & $\mathbf{n} *$ & $\%$ \\
\hline \multicolumn{3}{|c|}{ Expertise } \\
\hline Beginner & 6 & 1.6 \\
\hline Intermediate & 126 & 32.8 \\
\hline Advanced & 141 & 36.7 \\
\hline Expert & 111 & 28.9 \\
\hline \multicolumn{3}{|c|}{ Experience } \\
\hline Less than 1 year & 21 & 5.5 \\
\hline Between 1 to 3 years & 45 & 11.7 \\
\hline Between 3 to 5 years & 78 & 20.3 \\
\hline More than 5 years & 240 & 62.5 \\
\hline \multicolumn{3}{|c|}{ Duration } \\
\hline Less than 1 hour & 24 & 6.3 \\
\hline Between 1 to 3 hours & 40 & 10.4 \\
\hline Between 3 to 5 hours & 107 & 27.9 \\
\hline More than 5 hours & 213 & 55.5 \\
\hline \multicolumn{3}{|c|}{ Frequency } \\
\hline Rarely & 30 & 7.8 \\
\hline Often & 81 & 21.1 \\
\hline Sometimes & 84 & 21.9 \\
\hline Always & 189 & 49.2 \\
\hline
\end{tabular}

\subsection{Factor Analysis}

The analysis of the EFA test revealed that mean for the eighteen usability evaluation items were high with values above 3 . Respondents also indicated higher loading factor for the 
eighteen usability evaluation items with more than 65 . Higher values of mean and loading factor, thus shows higher perception towards the usability assessment items of defence android-based application system (refer to Table 3).

Table 3. Importance level and loading factor

\begin{tabular}{cccc}
\hline & Item & Mean & Factor \\
\hline Q7 & User Willingness & 3.54 & 0.73 \\
Q8 & Task Completion & 3.55 & 0.82 \\
Q9 & Error Correction & 3.78 & 0.85 \\
Q10 & Error Prevention & 3.71 & 0.84 \\
Q11 & Goal Achievement & 3.70 & 0.79 \\
Q12 & Skill Adaptation & 3.77 & 0.68 \\
Q13 & Task Timeliness & 3.55 & 0.86 \\
Q14 & Action Speed & 3.60 & 0.76 \\
Q15 & Usage Effort & 3.68 & 0.78 \\
Q16 & Movement Steadiness & 3.81 & 0.73 \\
Q17 & Position Stability & 3.92 & 0.76 \\
Q18 & Physical Reaction & 3.38 & 0.81 \\
Q19 & Emotional Feeling & 3.48 & 0.83 \\
Q20 & Mental Health & 3.70 & 0.77 \\
Q21 & Social Wellbeing & 3.83 & 0.80 \\
Q22 & Usage Productivity & 3.66 & 0.80 \\
Q23 & User Competency & 3.78 & 0.72 \\
Q24 & Self Satisfaction & 3.84 & 0.79 \\
\hline & & & \\
\hline
\end{tabular}

The analysis of the EFA test also revealed the three-factor structure model for assessing the usability of defence android-based application system. Nine usability evaluation items were found high strength with values more than 0.700 whereas remains were found moderate with values more than 400 (refer to Table 4). 
Table 4. Categorization of three-factor structure

\begin{tabular}{cccccc}
\hline & Item & \multicolumn{3}{c}{ Factor } & Strength \\
& & $\mathbf{1}$ & $\mathbf{2}$ & $\mathbf{3}$ & \\
\hline Q7 & User Willingness & - & - & 0.790 & High \\
Q8 & Task Completion & - & - & 0.688 & Moderate \\
Q9 & Error Correction & 0.586 & - & - & Moderate \\
Q10 & Error Prevention & 0.617 & - & - & Moderate \\
Q11 & Goal Achievement & 0.717 & - & - & High \\
Q12 & Skill Adaptation & - & 0.409 & - & Moderate \\
Q13 & Task Timeliness & - & - & 0.498 & Moderate \\
Q14 & Action Speed & 0.529 & - & - & Moderate \\
Q15 & Usage Effort & 0.773 & - & - & High \\
Q16 & Movement Steadiness & 0.863 & - & - & High \\
Q17 & Position Stability & 0.922 & - & - & High \\
Q18 & Physical Reaction & - & 0.726 & - & High \\
Q19 & Emotional Feeling & - & 0.835 & - & High \\
Q20 & Mental Health & - & 0.901 & - & High \\
Q21 & Social Wellbeing & - & 0.772 & - & High \\
Q22 & Usage Productivity & - & 0.662 & - & Moderate \\
Q23 & User Competency & - & 0.647 & - & Moderate \\
Q24 & Self Satisfaction & - & 0.691 & - & Moderate \\
\hline & & & & &
\end{tabular}

$\geq 0.700$-high relationship strength

$\geq 0.400$-moderate relationship strength

$\geq 0.000$-low relationship strength

The EFA process revealed the three-factor structure of Defence-MoASUES of Efficiency (EFY), Satisfaction (STF) and Effectiveness (EFF). The internal consistency reliabilities for the three factors ranged from 0.923 to 0.878 with high strength (refer to Table 5). 
Table 5. Factors of usability evaluation items

\begin{tabular}{ccccc}
\hline Item & \multicolumn{3}{c}{ Factor } & \\
& $\mathbf{1}$ & $\mathbf{2}$ & $\mathbf{3}$ & Strength \\
\hline Efficiency & 0.921 & - & - & High \\
Satisfaction & - & 0.923 & - & High \\
Effectiveness & - & - & 0.878 & High \\
\hline
\end{tabular}

$\geq 0.700$-high relationship strength

$\geq 0.400$-moderate relationship strength

$\geq 0.000$-low relationship strength

Therefore, results from the EFA test showed that the hypothesis respondent perceptions of the three-factor structure of Defence-MoASUES was accepted. The categorization of each items towards its corresponding factor is shown below (refer to Table 6).

Table 6. The categorization of the Defence-Moasues

\begin{tabular}{cc}
\hline Item of Defence-MoASUES \\
\hline Q17 & Efficiency \\
Q16 & Mosition Stability \\
Q15 & Usage Effort \\
Q11 & Goal Achievement \\
Q10 & Error Prevention \\
Q9 & Error Correction \\
Q14 & Action Speed \\
& Satisfaction \\
Q20 & Mental Health \\
Q19 & Emotional Feeling \\
Q21 & Social Wellbeing \\
Q18 & Physical Reaction
\end{tabular}




\begin{tabular}{cl} 
Q24 & Self Satisfaction \\
Q22 & Usage Productivity \\
Q23 & User Competency \\
Q12 & Skill Adaptation \\
& Effectiveness \\
Q7 & User Willingness \\
Q8 & Task Completion \\
Q13 & Task Timeliness \\
\hline
\end{tabular}

The three-factor model structure identified in the EFA was confirmed, thus providing evidence for the construct validity of Defence-MoASUES (see Fig. 4). The model that the three factors (EFY, STF and EFF) are explained by a broader dimension of the general factor (USB), and the general factor (USB) is able to predict a measured item, perception toward usability evaluation (PUEM). This finding provides evidence of factorial validity and internal consistency reliability through exploratory factor analysis. The customizability of Defence-MoASUES has the potential to support comparisons at the construct level, while allowing variation at the item level.

\section{CONCLUSION}

A customizable questionnaire (Defence-MoASUES) was developed for measuring perception toward usability evaluation. The results of exploratory factor analysis provided preliminary evidence for the factorial validity and internal consistency reliability of the Defence-MoASUES.

\section{ACKNOWLEDGEMENTS}

My thanks to Faculty of Science and Defence Technology, National Defence University of Malaysia, Centre of Research and Innovation, National Defence University of Malaysia, and Ministry of Higher Education, Malaysia. 


\section{REFERENCES}

[1] Davis F D. Perceived usefulness, perceived ease of use, and user acceptance of information technology. MIS Quarterly, 1989, 13(3):318-340

[2] Han S, Harkke V, Tétard F, Collan M. The performance of a mobile medical information system: Assessment by physicians undertaking compulsory military service. Journal on Information Technology in Healthcare, 2007, 5(3):171-181

[3] Han S, Harkke V, Tétard F, Collan M. Usability evaluation of a mobile medical information system for military physicians. In 40th IEEE Hawaii International Conference on System Sciences, 2007, pp. 1-9

[4] International Organization for Standardization (ISO). Ergonomic requirements for office work with visual display terminals. Geneva: ISO, 1991

[5] Lewis J R. IBM computer usability satisfaction questionnaires: Psychometric evaluation and instructions for use. International Journal of Human-Computer Interaction, 1995, $7(1): 57-78$

[6] Norman K L, Shneiderman B, Harper B D, Slaughter L A. Questionnaire for user interaction satisfaction. College Park: University of Maryland, 1989

[7] Venkatesh V, Morris M G, Davis G B. User acceptance of information technology: Toward a unified view. MIS Quarterly, 2003, 27(3):425-478

[8] Yen P Y, Sousa K H, Bakken S. Examining construct and predictive validity of the health-IT usability evaluation scale: Confirmatory factor analysis and structural equation modeling results. Journal of the American Medical Informatics Association, 2014, 21(e2): $241-248$

[9] Zali Z, Fadzlah A F A. Review of current usability models for assessing usability of mobile applications. In International Conference for Postgraduate Research, 2015

[10] Fadzlah A F A. Identifying measures for assessing the readiness of handheld application usage. Lecture Notes on Software Engineering, 2014, 2(3):256-261

[11] Fadzlah A F A. Metrics and attributes for assessing the stability of handheld application usage. In Information Systems International Conference, 2013, pp. 637-642

[12] Fadzlah A F A. Investigating timeliness measures: Towards measuring handheld 
application usage. In International Conference on Intelligent Network and Computing, 2011, pp. $1-5$

\section{How to cite this article:}

Fadzlah AFA. Developing customizable defence mobile application system usability evaluation scale (defence-moasues) using exploratory factor analysis (efa). J. Fundam. Appl. Sci., 2017, 9(3S), 91-104. 